\title{
Environmental and natural resources governance Rethinking public-private relationships
}

\author{
Carmen Maganda and Olivier Petit
}

Talking about environmental and natural resources (ENR) governance today is generally related to the search for holistic elements to achieve sustainability. Political ecology clearly points out and debates the need to see ENR, particularly those related to vital necessities, as global public goods. It sounds like an easy equation: How can we achieve sustainability without sharing access, costs, benefits, and of course governance of ENR needed for all human activities? However, as logical as it seems, development inequalities and unregulated market relationships on the management of these resources are still predominant. Therefore, environmental governance and sustainability is still one of the major contemporary global challenges.

This challenge is even of growing importance in the context of global climate/environmental change and the necessity to find a way to design multilevel governance processes throughout the entire planet, able to cover the large spectrum of biodiversity, water, and climate change impacts among other issues, is still a hot topic of interest for both scientists and policymakers.

In the search to study environmental governance not only as government, but also economy and society, we found Durant et al. (2004), who already stressed the need to design a New Governance Paradigm (NGP) for ENR management. According to these authors, this NGP can be synthetized with three important challenges facing ENR management in the twenty-first century: "First, success depends on reconceptualizing ENR management regimes in ways that better reflect ecological and public health risks and interdependencies. Second, these reconceptualized regimes must reconnect with stakeholders in the development, implemen- 
tation, and assessment of any policies that are pursued, and they must conscientiously consider vertical and horizontal equity both within and across generations. Third, not only must ENR management become more cost effective, risk-based, and results-oriented, but doing so requires fundamentally redefining what constitutes administrative rationality in both the public and private sectors" (Durant et al., 2004, p. 646). Others scholars have used different arguments to stress the necessity to build a new social contract between stakeholders in the governance of ENR. For instance, Bodin and Crona (2009) have shown that social networks' characteristics (density of relations, degree of cohesiveness, degree of network centralization, and subgroup interconnectivity) can have a differentiated impact on the governance of ENR and on the enforcement of the rules.

We could fill this introduction with many more important references, but with just these two, we want to indicate the line that we wish to follow in this special issue: rethinking the social public-private relationships behind ENR regimes. We believe it is always useful to develop discussions with related literature in order to dig deeper into analysis with concrete case studies and capture/understand the diverse range of dynamic forces driving the management of ENR.

This special issue ${ }^{1}$ proposes a cross view of environmental governance and public-private practices, from water, wetlands, environmental services, and agricultural reconfiguration examples. The issue includes methodological, theoretical, and empirical articles in order to promote interdisciplinary research and comparative analysis through regional and local environmental study cases. Therefore, the articles will show specific case-scenarios in Europe, Asia, and North America, most of them coming from applied research, including multidisciplinary approaches as rich as the contributors' diverse profiles.

The articles included in this special issued represent interesting samples of current research on the management of natural resources and the environment through the concepts of governance and public-private relationships. Some of the articles will specifically examine the evolution of rights-based debates between stakeholders and the role of the State, with particular focus on the analysis of public, collective and common goods and services. Among the questions at stake in the governance of ENR, the provision, management, and maintenance of public goods and services is always a topic of debate, particularly in developing countries which often lack access to basic needs (such as water), important for all development dynamics. Moreover, the status of stakeholders' participation in governance processes is also a key element that will be addressed in the articles of this special issue. Even if a very large literature has been developed on this topic, participation remains the central theme and a condition of suc- 
cess of governance issues. But, in order to implement participation, it is necessary to reconsider public and private (including here firms, but also NGOs and simple citizens) relationships, far beyond that which has already been engaged in most cases. Finally, because ecosystem services are becoming one of the central instruments of the Convention on Biological Diversity, ${ }^{2}$ and increasingly of the UN Framework Convention on Climate Change, the relationships between ecosystem services and governance will be addressed as well in this issue. All these topics concern the evaluation/assessment of environmental governance. Thus, a common theme that relates to most of the papers of this special issue is the development of evaluation/assessment methods (going beyond economic valuation) related to environmental governance.

Among other resources, water is by far one of the most studied cases in ENR governance levels. Following this introduction in this issue's first article, Catherine Baron and Muriel Maillefert present their research on water governance in French-speaking Africa questioning the hybridization of its practices. The authors show that the access/right to fresh water in developing countries is always a multilevel issue surrounded by public policies that successively privilege several models of access to water, not always with effectiveness and equity. With a rich case study behind them, Baron and Maillefert argue for and propose the need to construct collective rules of management and distribution of water services, as well as a comparative analysis of the processes of emergence and perpetuation of the water management institutions in certain countries of French-speaking Africa.

In the second article, and continuing with an institutional analysis, Joyce Valdovinos develops a multilevel governance scenario reflected on what she calls "the multi-level water space." Based on Mexico City, her contribution inserts some reflections into the conceptual debate on water as a public and/or private good and the need to build a multilevel water space to better address integrated water management with efficiency and plural participation.

Our third article on water governance comes from Aurélien Allouche and Laurence Nicolas on water rights tied to the Camargue insulate (located in France) and its flood risks. The authors show the administrative paradigm taken in the same public space-the hydraulic management system - the coordination of public-private water rights and planning actions mixed with technical system decisions. The authors clearly identify the inherent risk to prioritize the plurality of rights in order to manage the technical and natural constraints, and the risk to essentially exclude these aspects from public space/discussion.

The following two articles specifically address the issue of governance in relation to the provision, maintenance, and management of environ- 
mental services delivered by wetlands (Point) and agriculture stakeholders (Jeanneaux, Aznar, and Déprés). Since the United Nations' launching of the Millenium Ecosystem Assessment in early 2000, most of the environmental and natural resources management policies (at local, national, and global scales) have incorporated the necessity to conserve ecological functions of the ecosystems, important for human well-being. The notion of ecosystem service is clearly anthropocentric, and a large debate exists, particularly in the French literature, on the use of the most adequate expression: ecosystem vs. environmental services. The difference between these expressions reflects the recognition of human intervention in natural spaces and territories. "Environmental services" is preferred here by Jeanneaux et al. as well as by Point because the services analyzed in their papers (services delivered by agriculture and wetlands stakeholders) are clearly the results of a socio-ecological system, which couldn't exist without human intervention. The provision and maintenance of environmental services delivered by such socio-ecological systems is clearly a matter of governance and can be considered to be a public good (Point). In his article, Patrick Point considers the landowners' associations (Associations syndicales de propriétaires-ASP) as the production units of environmental services. Based on a sample of 20 ASP located in the Gironde Estuary (France), he analyzes the maintenance and investment costs of the infrastructures crafted and maintained by these ASP and shows the presence of economics of scale generated by these institutions that enable the production and maintenance of environmental services at low costs. The article by Jeanneaux, Aznar, and Déprés analyzes the various transactions operating in the agricultural sector as a way to compensate farmers for the environmental services generated (or coproduced) by their activity. Agriculture is often presented as a source of negative externalities and the growing importance of payments for environmental services is a way to recognize the beneficial role of farmers in the production and maintenance of environmental services. Nevertheless, as shown by Jeanneaux et al., not all the transactions that take place have the same roots. Moreover, the institutional framework that enables the recognition of farmers as coproducers of environmental services is often neglected. Thus, the governance of environmental services is a key element of their paper.

Because sustainability is not only politics and economics but should also include values from different forms of otherness included in humanenvironment relationships, we are also honored to present a particular contribution within the scope of environmental cultural anthropology. James Eder explores household economy transformations resulting from resource degradation and environmental reconfiguration in coastal and upland Southeast Asia, and the need for more profitable and sustainable 
rural livelihoods. Based on extensive and rich field research in the region, the author accepts the challenge of identifying what changes in environmental governance are needed to help make the particular environmental reconfiguration case study process more economically and ecologically beneficial and less harmful to people than it is today.

In the Leadership Forum section, we are proud to include an interesting reflective piece by Nadine Feyder on the importance of reinforcing the environmental governance capacity of the Democratic Republic of the Congo (DRC), both for the sustainability of its development paradigm and for the attainment of a firm international environmental governance.

She presents the DRC's rainforest basin as the second "lung" of the planet, after the Amazon, almost untouched due the repeated wars suffered during the last 20 years, but now seen as the target of growing national and international interest. Through this particular case, the author invites us to reflect on the development concept and paradigms linked to a direct trade-off between poverty reduction and the preservation of natural resources.

We kindly invite you to read and hopefully enjoy this first special issue of Regions $\mathcal{E}$ Cohesion. We are open to all comments and suggestions that you, the readers, wish to transmit to us, the guest editors, and our RISC working group.

\section{NOTES}

1. All the articles included on this special issue are related to the discussions of the RISC working group on Management of Strategic Resources: Environment and Society (for further information please see http://www.risc.lu). Most of the contributions are particularly coming from the working group's international workshop on Environment, Regions and Strategic Resources: Governance Models for Rights-Based Perspectives, held in July 2010 in Lille (France), coordinated by the editors of this issue with the invaluable help of Constanza Parra. Therefore, we still want to thank the following institutions for their financial and administrative support: the Université de Lille 1, CLERSE (UMR 8019 CNRS-Univ. Lille1), the RISC Consortium, Institut Ecologie et Environnement du CNRS, the Mission Prospective du Ministère français de l'Ecologie, de l'Energie, du Développement Durable et de la Mer (MEEDDM), the Conseil Régional Nord-Pas-de-Calais, the Parc Naturel Régional Scarpe Escaut, the Parc naturel transfrontalier du Hainaut, and of course the Maison européenne des SHS of Lille where the meeting was held.

A special thank you to all the workshop participants and their immensely appreciated contributions to our multidisciplinary working group debate. The event was so academically rich and productive that besides this special issue we are working simultaneously on a forthcoming book on a simi- 
lar topic, with another group of interesting papers deriving from the same symposium.

2. See the outcomes of the Convention on Biological Diversity's (CBD) Conference of the Parties in Nagoya, 2010.

\section{REFERENCES}

Bodin O., \& Crona, B.I. (2009). The role of social networks in natural resource governance: What relational patterns make a difference? Global Environmental Change, 19 (3), 366-374.

Durant R.F., Young-Pyoung, C., Byungseob, K., \& L. Seongjong (2004). Toward a new governance paradigm for environmental and natural resources management in the 21st century?, Administration \& Society, 35 (6), 643-682. 